\title{
Understanding the Reinforcing Mechanisms in Kenaf Fiber/PLA and Kenaf Fiber/PP Composites: A Comparative Study
}

\author{
Seong Ok Han, ${ }^{1}$ Mehdi Karevan, ${ }^{2}$ I. Na Sim, ${ }^{1}$ Md A. Bhuiyan, ${ }^{2}$ Young Hun Jang, ${ }^{1}$ \\ Jonathan Ghaffar, ${ }^{2}$ and Kyriaki Kalaitzidou ${ }^{2}$ \\ ${ }^{1}$ Functional Materials Research Center, Korea Institute of Energy Research, 71-2 Jang-dong, Yuseong-gu, \\ Daejeon 305-343, Republic of Korea \\ ${ }^{2}$ G. W. Woodruff School of Mechanical Engineering, Georgia Institute of Technology, Atlanta, GA 30332, USA
}

Correspondence should be addressed to Kyriaki Kalaitzidou, kyriaki.kalaitzidou@me.gatech.edu

Received 14 April 2012; Revised 13 July 2012; Accepted 16 July 2012

Academic Editor: Alain Dufresne

Copyright (C) 2012 Seong Ok Han et al. This is an open access article distributed under the Creative Commons Attribution License, which permits unrestricted use, distribution, and reproduction in any medium, provided the original work is properly cited.

\begin{abstract}
This study focused on exploring the feasibility of green composites made from biodegradable and renewable materials as potential alternatives to petroleum polymer composites and understanding the reinforcing mechanisms in composites containing kenaf fibers (KF). KF-reinforced poly(lactide) acid (PLA) composites were made using melt compounding and injection molding, and their properties were compared to that of KF-reinforced polypropylene (PP) composites. The flexural properties and thermomechanical behavior were determined as a function of the fiber content, the crystallization of PLA and PP was studied using X-ray diffraction and differential scanning calorimetry, and the composites' morphology was investigated using scanning electron microscopy. It was concluded that PLA exhibits higher modulus and Tg compared to those of neat PP. The modulus of the composites at $40 \mathrm{wt} \%$ fibers is $6.64 \mathrm{GPa}$ and $2.96 \mathrm{GPa}$ for PLA and PP, respectively. In general, addition of kenaf results in larger property enhancement in PP due to better wetting of the fibers by the low melt viscosity PP and the crystallization behavior of PP that is significantly altered by the fibers. The novelty of this work is that it provides one-to-one comparison of PLA and PP composites, and it explores the feasibility of fabricating green composites with enhanced properties using a simple scalable process.
\end{abstract}

\section{Introduction}

Increased trend for sustainable and environmentally friendly materials leads the polymer composites academic and industrial communities towards biodegradable polymers from renewable resources such as poly (lactide) acid (PLA) [1], which recently has become very popular. PLA is an ecofriendly thermoplastic polyester with properties comparable if not better to those of petroleum-based thermoplastics [2$4]$. It possesses relatively high melting point [5] and can exhibit good mechanical performance [6]. PLA-based composites have successfully been made and characterized using various reinforcements including natural fibers [6-10], nanomaterials such as carbon nanotubes [11, 12], graphite [7, 13-16], carbon nanofibers [15], and clays [17-19].

Combining PLA with natural fibers, which are abundantly available such as kenaf, jute, or sisal, can lead to a totally green composite made only from renewable resources.
The unique features of natural fibers are the high specific strength and modulus and large elongation at failure [20], and their low cost $(\$ 0.44-\$ 0.55 / \mathrm{kg}$ compared to $\$ 2.00-$ $\$ 3.25 / \mathrm{kg}$ for E-glass fibers) [21], which make them potential candidates for replacing traditional reinforcements such as glass fibers which are costly and have much larger density. The limitation in the widespread application of natural fibers as reinforcements for polymers is the inconsistency in their properties which depend strongly on the conditions of growth, high moisture absorption [22], and incompatibility with some polymeric matrices. The approach commonly followed in order to overcome the above limitations is to either surface treat the fibers [23-25] or add compatibilizers and coupling agents such as maleic anhydride, acetic anhydride, and silanes [26], which can facilitate better fiber-polymer interfacial interactions and efficient load transfer.

It has been reported $[20,21]$ that the mechanical properties of PP composites reinforced with natural fibers 
compared favorable to the corresponding properties of PP composites reinforced with glass fibers indicating that natural fibers have great potential to replace glass in composites that do not need to exhibit very high load bearing capabilities. PLA has been proposed as an alternative to engineering thermoplastics mainly PP, but there is lack of studies that show one- to one-comparison of PLA and PP composites.

This study focuses on providing a direct performance comparison between kenaf fiber/PLA and kenaf fiber/PP composites made by extrusion injection molding, which are simple low cost and scalable processes of manufacturing composites without using any special fiber treatment or compatibilizers that add complexity to the process and increase the cost. Furthermore, absence of compatibilizers and use of as-received kenaf fibers will allow to study the fiber-polymer interactions and elucidate the reinforcing mechanisms. PP is an inert nonpolar polymer with no functional groups, whereas PLA is a polyester with carboxyl groups at the ends of the polymer chains. No chemical interactions are expected between the fibers and either of the polymers. The study explores the potential of using totally green composites made from renewable resources in engineering applications. In conclusion, the novelty of this work is twofold: (i) it provides one-to-one comparison of kenaf-fiber-reinforced PLA and PP composites and (ii) it explores the feasibility of fabricating green composites with enhanced properties using a simple scalable process, that is conventional melt mixing and injection molding, without the need for costly or toxic solvents and chemicals. The importance of the direct oneto-one comparison of the two matrices is that $\mathrm{PP}$ is one of the most commonly used thermoplastics in engineering applications, so replacing PP with biodegradable polymers such as PLA can lead to environmentally friendly materials and green technologies.

\section{Experimental}

2.1. Materials and Fabrication of Composites. Semicrystalline poly (lactic acid), (PLA 3051D, MW $=1.42 \times 10^{4} \mathrm{~g} / \mathrm{mol}$, melt flow index $7.75 \mathrm{~g} / 10 \mathrm{~min}$ ) in pellet form was purchased from Nature Works LLC (Minnesota, MN), product code 3051D. Polypropylene powder (Pro-fax 6301, melt flow index $12 \mathrm{~g} / 10 \mathrm{~min}$, isotactic $>90 \%$ ) by Basell was purchased from PolyOne. Kenaf (Hibicus canabinus L.) fibers in the 60$70 \mathrm{~mm}$ filament form and a diameter of $0.08-0.1 \mathrm{~mm}$ were supplied from Bangladesh. The kenaf fibers were cut at a length of $10 \mathrm{~mm}$ and used without further treatment. It is noted that the kenaf fibers are nonwood lignocellulose materials that contain cellulose, hemicellulose, and lignin [27].

The composites were made by melt mixing the Kenaf fibers with the PLA pellets or the PP powder using a twinscrew (counter corotating) extruder ( $15 \mathrm{cc}$, DSM, Netherlands). The screw speed was $150 \mathrm{rpm}$, the material residence time in the extruder was set to $3 \mathrm{~min}$ and the barrel temperature was $180^{\circ} \mathrm{C}$. Specimen coupons were made by injection molding with the temperature of the mold $T_{\text {mold }}=75^{\circ} \mathrm{C}$ and molding pressure (injection, filling, and packing) of 110 psi. The kenaf fiber content used was $0,20,30$, and $40 \mathrm{wt} \%$.

2.2. Characterization. The flexural strength and modulus were determined using a three-point bending test, at a strain rate of $0.01 / \mathrm{min}$, according to ASTM D790 using an MTS machine. The specimens were deflected until rupture occurred in their outer surface or until a maximum strain of 5.0\% was reached, whichever occurred first. The storage modulus and tan delta of the composites were measured by dynamic mechanical analysis (DMA, Q800, TA Instruments) using nitrogen atmosphere, with a single cantilever mode. A heating rate of $5^{\circ} \mathrm{C} / \mathrm{min}$ was used. The temperature range was from ambient to $150^{\circ} \mathrm{C}$. The tests were conducted at oscillation amplitude of $0.02 \mathrm{~mm}$ and a fixed frequency of $1 \mathrm{~Hz}$. Before each measurement, the instrument was calibrated to have the correct clamp position and clamp compliance.

The morphology of the composites including the dispersion and distribution of the fibers within the polymer and the existence of voids at the fiber/polymer interface was characterized by SEM (S-4700, Hitachi, Japan) at an acceleration voltage of $15-25 \mathrm{kV}$. The surfaces studied were obtained by cryo-fracture using liquid nitrogen. Prior to the observation, the specimens were coated with Au to prevent surface charging. The effect of kenaf fibers on the crystallization behavior of PLA and PP was studied using X-ray diffraction and differential scanning calorimetry (DSC). In the DSC study, the samples used were $5-10 \mathrm{mg}$ and were heated at $5^{\circ} \mathrm{C} / \mathrm{min}$ from ambient temperature to $220^{\circ} \mathrm{C}$. The temperature was held at $220^{\circ} \mathrm{C}$ for $5 \mathrm{~min}$ and then decreased to ambient at a rate of $5^{\circ} \mathrm{C} / \mathrm{min}$. The X-ray diffraction patterns of the composites were obtained using a Rigaku Rotaflex 200B diffractometer employing $\mathrm{Cu}$-Ka radiation $(k=1.54056 \AA)$ with a curved graphite monochromator. The operating setting of the X-ray was $45 \mathrm{kV}$ and $100 \mathrm{~mA}$. The diffraction patterns were collected from $8^{\circ}$ to $50^{\circ}(2 \mathrm{~h})$ at a scanning rate of $1 \%$ min with divergence and scatter slit of $1 / 4^{\circ}$ and $1 / 2^{\circ}$, respectively.

\section{Results and Discussion}

The flexural strength and modulus of kenaf fiber/PLA and kenaf fiber/PP composites as a function of the kenaf fiber content are presented in Figure 1. First it is noted that PLA has significantly higher strength and modulus compared to those of neat PP or even those of kenaf fiber/PP composites for all fiber contents investigated. The modulus of both polymers increases upon addition of kenaf fibers with the largest improvement, in the order of $300 \%$, achieved in $40 \mathrm{wt} \%$ kenaf/PP composites when the modulus enhancement of the corresponding PLA composites is about $120 \%$. Similarly, the relative strength enhancement is higher in the PP composites but PLA composites exhibit larger absolute strength values for all fiber contents investigated. It is also noted that the strength does not increase significantly with fiber content in case of PLA composites whereas in case of PP composites it reaches a plateau at $30 \mathrm{wt} \%$ of fibers. 


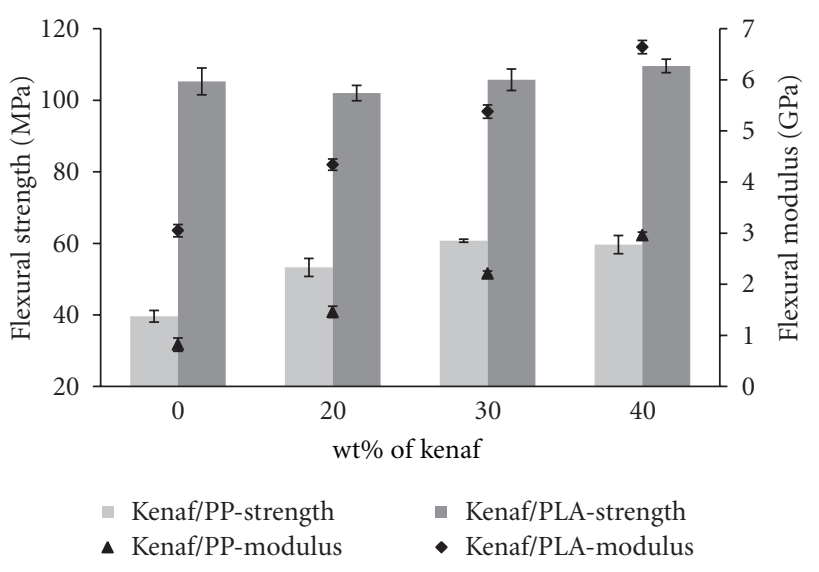

Figure 1: Flexural modulus and strength of kenaf/PP and kenaf/ PLA composites as a function of kenaf content.

The larger property enhancement observed in PP, compared to that in PLA, may indicate better wetting of the kenaf fibers due to the lower melt viscosity (PP has melt flow index of $12 \mathrm{~g} / 10 \mathrm{~min}$ compared to $7.75 \mathrm{~g} / 10 \mathrm{~min}$ of PLA) of $\mathrm{PP}$ and thus stronger fiber-polymer interactions as reported also elsewhere [21]. The mechanism for the enhancement of strength is closely related to the fiber-polymer interfacial interactions and considering that the fiber surface is not treated and no compatibilizers and coupling agents are used; it is expected that the strength will not be improved significantly. In conclusion, the strength in case of kenaf/PP composites is enhanced because the lower viscosity of PP allows for better wetting of the fibers so more efficient contact at the kenaf-PP interface that dominates the stress transfer and thus the strength. In case of PP, the strength reaches a plateau value at fiber content of $30 \mathrm{wt} \%$. This is expected because although no agglomeration was observed by SEM, as the fiber content increases there is more fiber surface that needs to be wetted by the polymer in order to have good contact and sufficient stress transfer, and less polymer that is available to wet the fibers, so the strength should either reach a plateau value or start decreasing upon further addition of fibers. The modulus is increasing in both polymers upon addition of the fibers because kenaf fibers have significantly higher modulus, $\sim 70 \mathrm{GPa}$ due to the high cellulose content $[28,29]$.

The dispersion and distribution of the fibers within the two polymers were studied using SEM. Representative SEM images are shown in Figure 2. The microstructure of the neat polymers is also shown for comparison. PLA (Figure 2(a)) appears to be more brittle than PP (Figure 2(b)). There is significant pull out of the fibers in both PLA and PP composites as shown in Figures 2(c) and 2(d). The smooth fiber surface shown in Figures 2(e) and 2(f) indicates weak interactions and poor adhesion between the fibers and the polymer matrices for both polymers. However, the strength increased in case of PP composites because as shown in Figure 6 and Table 2, the fibers act as nucleating agent and promote the nucleation of the less common $\beta$ phase, which has higher impact strength and toughness providing thus a
TABLE 1: Degree of crystallinity of PLA and PP composites as a function of fiber content.

\begin{tabular}{lcc}
\hline Fiber wt $\%$ & PLA & PP \\
\hline 0 & $32.03 \pm 0.58$ & $38.16 \pm 1.71$ \\
20 & $33.08 \pm 3.65$ & $39.98 \pm 3.69$ \\
40 & $34.02 \pm 0.26$ & $37.79 \pm 2.04$ \\
\hline
\end{tabular}

secondary reinforcing mechanism. Fiber agglomeration was not observed in either of the polymers. In general, besides the more brittle nature of PLA, there were no significant differences in the morphology of the PLA and PP composites.

The storage modulus and tan delta of kenaf fiber/PLA and kenaf fiber/PP composites as a function of kenaf fiber content for temperature ranging from $-30^{\circ} \mathrm{C}$ to $150^{\circ} \mathrm{C}$ are shown in Figures 3 and 4, respectively. For both composite systems, addition of kenaf fibers increases the storage modulus of the neat polymers throughout the temperature regime studied. For constant fiber content, the modulus slightly decreases with temperature for temperatures below the glass transition temperature, $T_{g}$, of the polymers. $T_{g}$ is defined as the temperature at which the tan delta obtains its maximum value and as shown in Figures 3 and 4 is $\sim 3-4^{\circ} \mathrm{C}$ and $93^{\circ} \mathrm{C}$ for PP and PLA, respectively. Corresponding values reported in literature are $0-10^{\circ} \mathrm{C}$ for $\mathrm{PP}$ [33] and $\sim 65^{\circ} \mathrm{C}$ for PLA [8]. It is noted that the measured value of $T_{g}$ depends on the molecular weight of the polymer, on its thermal history and age, on the measurement method, and on the rate of heating or cooling $[34,35]$. In case of PP, the $T_{g}$ values also depend on its tacticity. It is noted that the small shifts in $T_{g}$ of both polymers upon addition of kenaf fibers is of no significance and is typical in semicrystalline polymers where the transition actually occurs over a range of temperatures. At temperatures larger than $T_{g}$, there is a dramatic steplike drop in the storage modulus of PLA and PLA composites for all fiber contents used, whereas the modulus gradually drops in case of PP and PP composites. It becomes clear that PLA and its composites behave more viscous-like than elastic at higher temperatures. It is noted that the storage modulus of PLA and PLA composites goes through a steplike decrease with temperature, whereas the corresponding decrease in case of PP and PP composites is more gradual. The reason is that the rubbery regime $\left(T_{m}-T_{g}\right)$ of $\mathrm{PP}$ is significantly longer.

The effect of kenaf fibers on the crystallization behavior of PP and PLA composites, investigated using DSC and X-ray diffraction techniques, is summarized in Table 1 and Figures 5 and 6 . The degree of crystallinity was calculated using the following equation:

$$
X \%=\frac{\Delta H}{\Delta H_{m}^{\circ}(1-(\mathrm{wt} \% / 100))} \times 100,
$$

where $\Delta H_{m}^{\circ}$ is the theoretical crystallization enthalpy of the matrix if it was $100 \%$ crystalline. The values used are $93 \mathrm{~J} / \mathrm{g}$ and $209 \mathrm{~J} / \mathrm{g}$ for PLA and PP matrix, respectively $[1,36]$. Addition of kenaf fibers does not have any significant effect on the degree of crystallinity of PLA or PP as shown in Table 1. The fibers act as nucleating agent for both PLA 


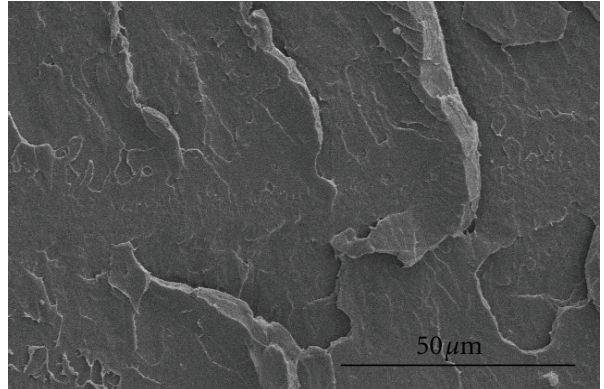

(a)

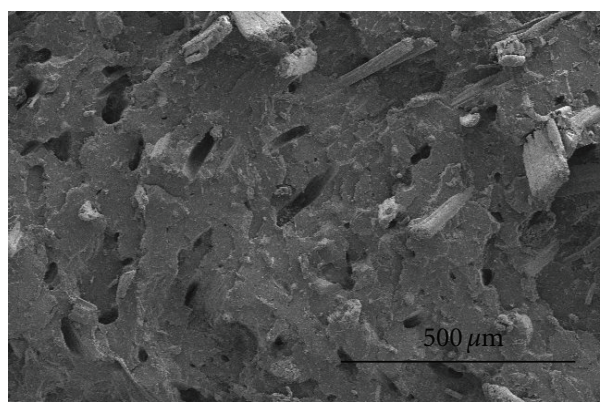

(c)

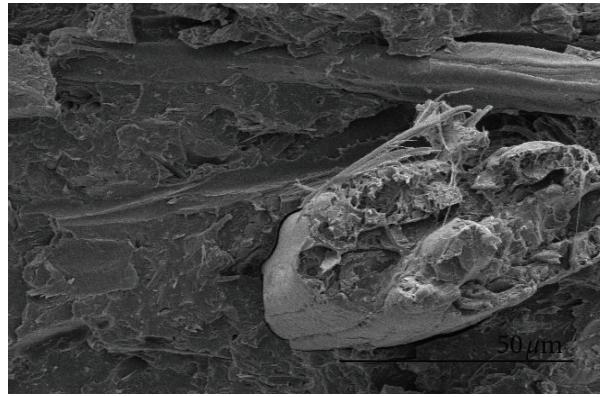

(e)

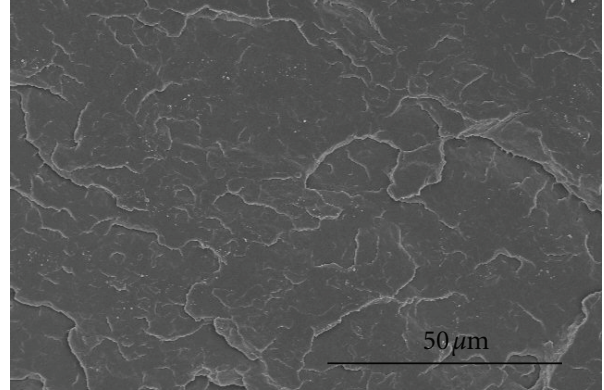

(b)

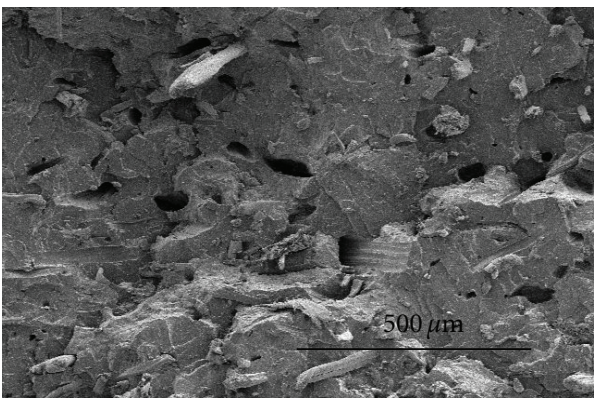

(d)

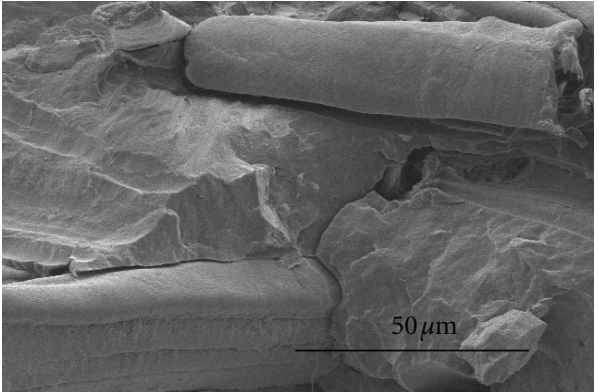

(f)

Figure 2: SEM micrographs of cry-fractured surface of (a) PLA, (b) PP, (c) 20 wt $\%$ kenaf/PLA, (d) 20 wt $\%$ kenaf/PP, (e) 30 wt\% kenaf/PLA, and (f) $30 \mathrm{wt} \% \mathrm{kenaf} / \mathrm{PP}$ composites.

TABLE 2: Peak temperatures of the neat PLA, PP and their composites.

\begin{tabular}{lccccc}
\hline & $T_{1}\left({ }^{\circ} \mathrm{C}\right)$ & $T_{c c}\left({ }^{\circ} \mathrm{C}\right)$ & $T_{m 1}\left({ }^{\circ} \mathrm{C}\right)$ & $T_{m 2}\left({ }^{\circ} \mathrm{C}\right)$ & $T_{m}\left({ }^{\circ} \mathrm{C}\right)$ \\
\hline Neat PLA & $60.62 \pm 0.59$ & $113.21 \pm 0.72$ & - & - & $147.84 \pm 1.01$ \\
20 wt\% kenaf/PLA & $59.43 \pm 0.21$ & $98.17 \pm 0.12$ & $140.54 \pm 0.29$ & $149.91 \pm 0.32$ & - \\
$40 \mathrm{wt} \%$ kenaf/PLA & $58.26 \pm 0.52$ & $92.54 \pm 0.76$ & $138.94 \pm 0.79$ & $148.54 \pm 0.64$ & - \\
Neat PP & & & & $167.86 \pm 0.02$ & $117.78 \pm 0.02$ \\
20 wt\% kenaf/PP & & & & $167.63 \pm 0.43$ & $124.19 \pm 0.53$ \\
$40 \mathrm{wt} \%$ kenaf/PP & & & & $166.88 \pm 0.49$ & $125.63 \pm 0.02$ \\
\hline
\end{tabular}

$T_{1}$ : the first peak temperature; $T_{c c}$ : cold crystallization; $T_{m 1}$ : the first melting point; $T_{m 2}$ : the second melting point; $T_{m}:$ melting temperature and $T_{c}$ : crystallization temperature.

and $\mathrm{PP}$ as indicated by the change in the crystallization temperature shown in Figures 5(a) and 5(b), respectively. Specifically, in case of PLA, the crystallization temperature recorded during the heating cycle decreases with fiber content whereas the crystallization temperature recorded during the cooling cycle of PP shifts to higher values with fiber content, both indicating nucleating effect. The results are in agreement with other studies reporting the nucleating effect of kenaf fibers in PP [37] and PLA [38] and the presence of a transcrystalline zone form at the fiber-polymer interface in case of PP [37]. It is noted that PLA does not crystallize during cooling but only during heating $[39,40]$. In case of PLA and PLA composites, there is an additional peak present at low temperatures in the heating cycle, which reflects the 
TABLE 3: Characteristic XRD peaks and corresponding crystallographic planes of kenaf/PP composites.

\begin{tabular}{|c|c|c|c|c|c|}
\hline $\mathrm{PP}$ & $20 \mathrm{wt} \%$ kenaf/PP & $30 \mathrm{wt} \%$ kenaf/PP & $40 \mathrm{wt} \%$ kenaf/PP & $\alpha$-form [30-32] & $\beta$-form $[31]$ \\
\hline \multirow[t]{2}{*}{13.97} & 14.04 & 14.1 & 14.1 & $<110>$ & \\
\hline & 16 & 16.07 & 16.04 & & $<300>$ \\
\hline 16.77 & 16.77 & 16.84 & 16.82 & $<040>$ & \\
\hline 18.38 & 18.39 & 18.45 & 18.51 & $<130>$ & \\
\hline 20.92 & 20.82 & 20.85 & & $<111>$ & $<301>$ \\
\hline 21.62 & 21.52 & 21.53 & 21.67 & $<041>$ & \\
\hline 25.16 & 25.01 & 25.13 & 25.15 & $<060>$ & \\
\hline 28.01 & 28.07 & 28.07 & 28.07 & $<220>$ & \\
\hline
\end{tabular}

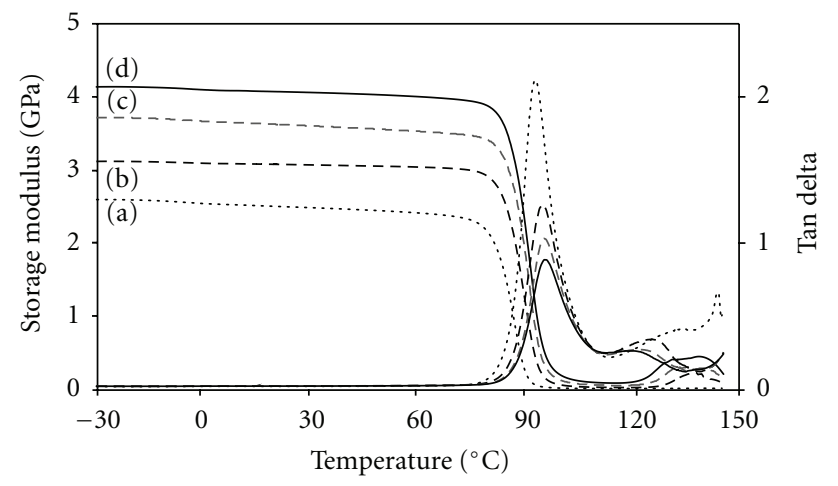
(a) PLA matrix
(c) $30 \mathrm{wt} \% \mathrm{KE} / \mathrm{PLA}$
(b) $20 \mathrm{wt} \% \mathrm{KE} / \mathrm{PLA}$

(d) $40 \mathrm{wt} \% \mathrm{KE} / \mathrm{PLA}$

Figure 3: Storage modulus and tan delta of kenaf fiber/PLA as a function of kenaf content and temperature.

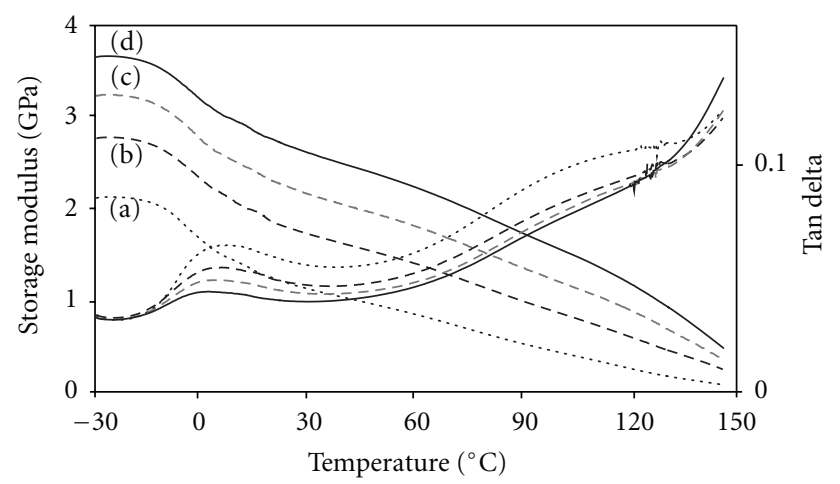
(a) PP matrix
(c) $30 \mathrm{wt} \% \mathrm{KE} / \mathrm{PP}$
(b) $20 \mathrm{wt} \% \mathrm{KE} / \mathrm{PP}$
(d) $40 \mathrm{wt} \% \mathrm{KE} / \mathrm{PP}$

Figure 4: Storage modulus and tan delta of kenaf fiber/PP as a function of fiber content and temperature.

glass transition a phenomenon that is related to the physical aging of the polymer matrix. Such a peak is absent from the heating curve of PP and its composites because the $T_{g}$ is below the temperature regime used in the DSC study. The other peaks present in the heating cycle of PLA and PLA composites are (i) the cold crystallization peak observed near the onset of melting at $\sim 113^{\circ} \mathrm{C}$ for the neat PLA, that decreases to $98^{\circ} \mathrm{C}$ and $92^{\circ} \mathrm{C}$ for 20 and $40 \mathrm{wt} \%$ kenaf fiber content, respectively, and (ii) two melting peaks for the PLA composites which in absence of kenaf fibers they merge into one at $\sim 147^{\circ} \mathrm{C}$. Presence of two melting points is attributed to size distribution of crystalline lamella if the melting points are not produced due to the matrix polymorphism.

Furthermore, there is a significant change in the melting behavior of PLA due to the presence of fibers, as shown in Figure 5(a). The single melting peak observed at $\sim 150^{\circ} \mathrm{C}$ in case of neat PLA is shifting at lower temperatures upon addition of fibers, and a second minor peak appears in the $135-140^{\circ} \mathrm{C}$ range. Both peaks shift to lower temperatures as the fiber content increases. The second peak may correspond to either a different PLA crystal type formed only in presence of the fibers, a hypothesis that will be tested based on X-ray analysis or maybe due to melting of the transcrystalline zone or recrystallization. The peak temperatures are presented in Table 2.

The effect of the kenaf fibers on the crystallization behavior of the PLA and PP was also studied using X-ray diffraction as shown in Figures 6(a) and 6(b), respectively. The diffraction pattern of neat fibers (curve A) is also shown for comparison. As shown in Figure 6(a), there is only one broad peak with maximum at $2 \theta=16.54^{\circ}$ for PLA that remains unaffected upon addition of kenaf fibers. The second peak at $\sim 21.7^{\circ}$, that is, present in case of the PLA composites corresponds to the kenaf fibers. It is noted that the intensity of this peak increases with the fiber content.

The characteristic XRD peaks and the corresponding crystallographic planes for $\mathrm{PP}$ and kenaf fiber/PP composites are presented in Table 3. The crystalline forms of isotactic PP are $\alpha$-monoclinic which is the most commonly observed, $\beta$-hexagonal, which occurs under specific conditions that is, temperature gradients, shearing forces or $\beta$-nucleating agents, and $\gamma$-triclinic, which is the least common observed in low molecular weight PP [30]. As shown in Table 3, the peak at $2 \theta=16^{\circ}$, which is one of the two characteristic peaks, which corresponds to the $<300>$ plane, of the $\beta$-form crystals is only present in the diffraction pattern of the PP composites. The second peak of the $\beta$-phase at $2 \theta=21^{\circ}$, that corresponds to the $<301>$ crystallographic plane, although present, it cannot be clearly detected due overlapping with a peak at the same angle of the $\alpha$-phase at $2 \theta=21^{\circ}$. Thus, it is concluded that kenaf fibers promote the nucleation of the less common $\beta$-phase crystals which have higher impact strength 


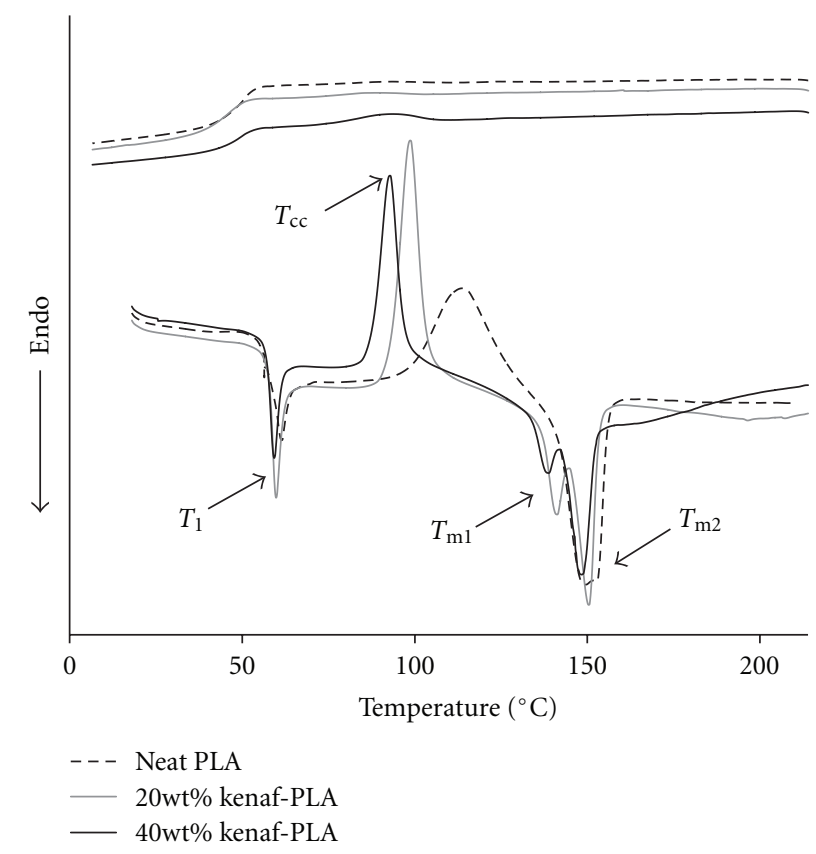

(a)

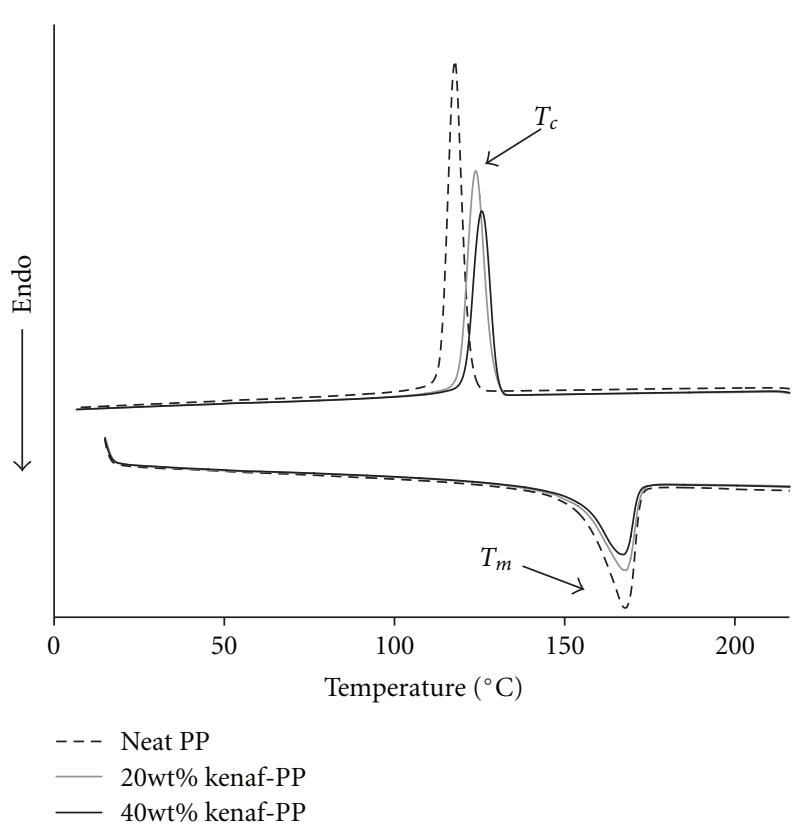

(b)

FIgURE 5: Differential scanning calorimetry: heating and cooling traces of (a) PLA and PLA composites and (b) PP and PP composites.

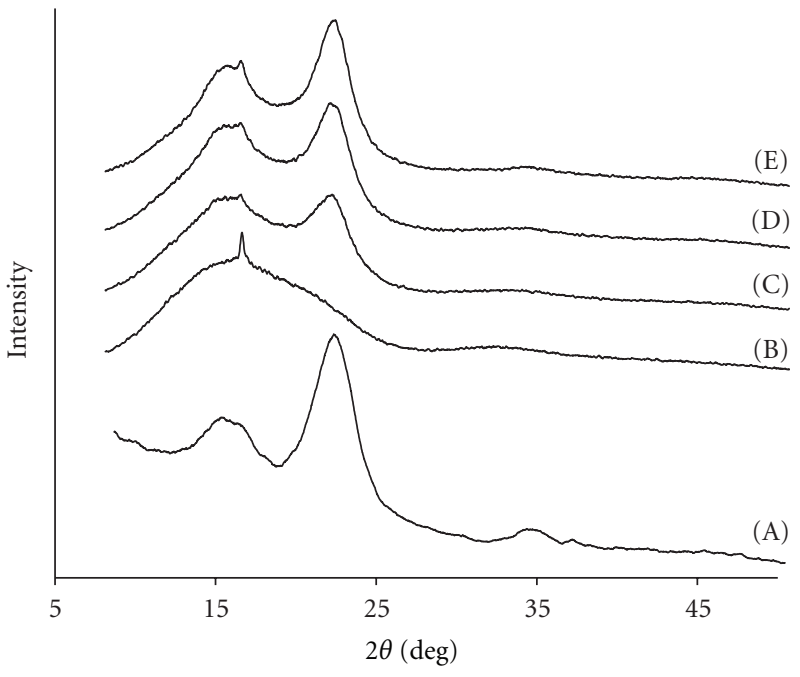
(A) Neat kenaf
(B) Neat PLA
(C) PLA $+20 w t \%$ kenaf
(D) PLA $+30 w t \%$ kenaf
(E) PLA $+40 w t \%$ kenaf

(a)

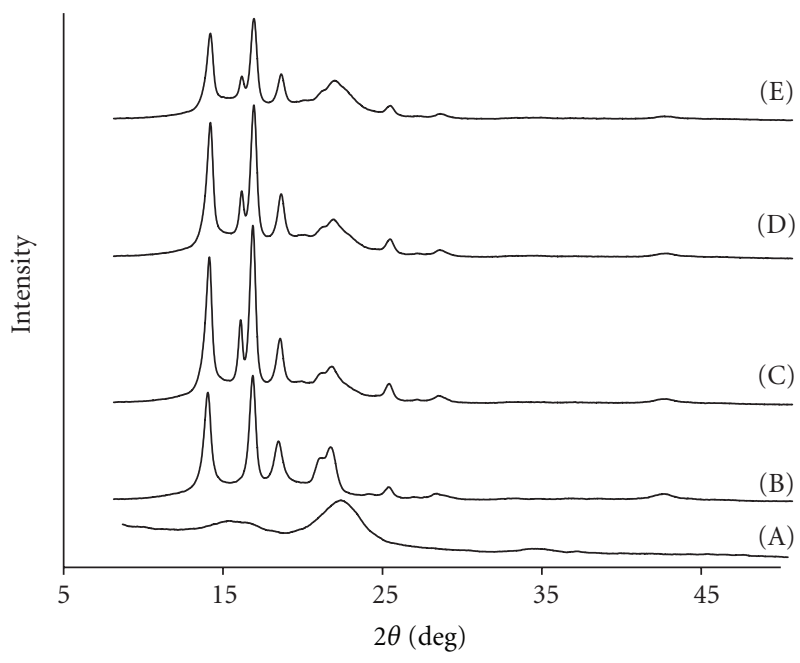
(A) Neat kenaf
(B) Neat PP
(C) PP + 20wt $\%$ kenaf
(D) $P P+30 w t \%$ kenaf
(E) PP + 40wt \% kenaf

(b)

FIGURE 6: XRD pattern of kenaf fibers and (a) PLA composites and (b) PP composites.

and toughness [41] providing thus a secondary reinforcing mechanism. The thermogravimetric analysis for PP and PLA composites as a function of the kenaf fiber content is presented in Figures 7 and 8, respectively. The temperature scale starts from $150^{\circ} \mathrm{C}$ to allow higher resolution of the temperature range we are interested in. No weight loss was observed below this temperature indicating that there was no water absorbed in the kenaf fibers. The main decomposition peak for PP was found at $\sim 448^{\circ} \mathrm{C}$, which in presence of kenaf fibers shifted slightly to higher temperatures. There are two additional peaks in the thermogram of the kenaf fiber/PP composites in the range of $270-290^{\circ} \mathrm{C}$ and $340-360^{\circ} \mathrm{C}$ that correspond to the decomposition of the hemicellulose and cellulose components in the kenaf fibers, respectively. The obtained TGA results are in agreement with results reported elsewhere [25]. 


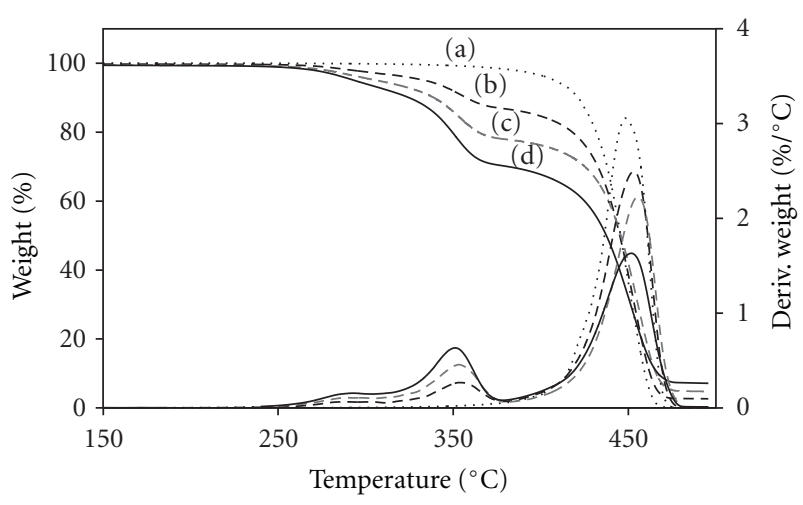

$\begin{array}{ll}\text { (a) PP matrix: } 448.48^{\circ} \mathrm{C} & \text { (c) } 30 \mathrm{wt} \% \mathrm{KE} / \mathrm{PP}: 455.46^{\circ} \mathrm{C}\end{array}$

$\begin{array}{ll}\text { (b) } 20 \mathrm{wt} \% \mathrm{KE} / \mathrm{PP}: 453.15^{\circ} \mathrm{C} & \text { (d) } 40 \mathrm{wt} \% \mathrm{KE} / \mathrm{PP}: 451.67^{\circ} \mathrm{C}\end{array}$

Figure 7: Thermogravimetric analysis of PP and PP composites.

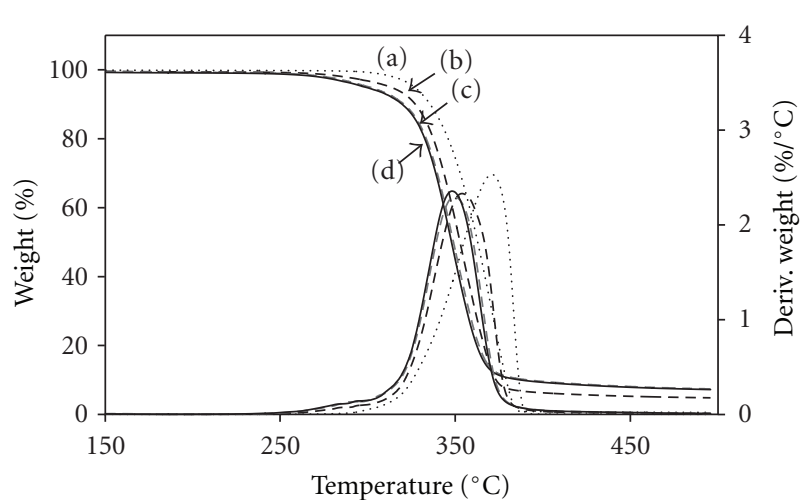

(a) PLA matrix: $370.83^{\circ} \mathrm{C}$

(c) $30 \mathrm{wt} \% \mathrm{KE} / \mathrm{PLA}: 349.39^{\circ} \mathrm{C}$

$\begin{array}{ll}\text { (b) } 20 \mathrm{wt} \% \mathrm{KE} / \mathrm{PLA}: 353.3 .78^{\circ} \mathrm{C} & \text { (d) } 40 \mathrm{wt} \% \mathrm{KE} / \mathrm{PLA}: 348.07^{\circ} \mathrm{C}\end{array}$

FIgURE 8: Thermogravimetric analysis of PLA and PLA composites.

\section{Conclusions}

Kenaf fiber/PLA and kenaf fiber/PP composites were made by melt mixing and injection molding, and their flexural and thermomechanical properties were determined as a function of the fiber content. It was found that the PLA has higher flexural strength, and modulus and higher storage modulus compared to PP. The same trend was observed for the PLA and PP composites although the addition of fibers resulted in larger property enhancement in case of PP. The improvement in the flexural modulus, flexural strength and storage modulus of PP at ambient temperature due to addition of $40 \mathrm{wt} \%$ kenaf fibers was $\sim 260 \%, 50 \%$, and $134 \%$, respectively, whereas the corresponding enhancement of properties for PLA was $118 \%, 4 \%$, and $64 \%$, respectively.

This large property enhancement indicates more favorable interactions between the fibers and the PP chains, which are a result of the lower melt viscosity of PP compared to that of PLA and lead to better fiber wetting. It was found that kenaf fibers act as nucleating agent for both polymers. The basic conclusion and major finding of the XRD analysis is that kenaf fibers promote the nucleation of the less common $\beta$ crystal phase in case of PP which, however, has higher strength and toughness than the most commonly occurring $\alpha$ phase crystals providing thus a secondary reinforcing mechanism (in case of PP). Morphological study based on SEM did not indicate any significant differences in the dispersion and distribution of the fibers within the two polymers and did not show any difference in the fiber pull out that reflects the interfacial adhesion between the two composite systems.

\section{Acknowledgments}

This work was financially supported by the Carbon Dioxide Reduction and Sequestration (CDRS) R\&D Center (the 21st Century Frontier R \& D Program) funded by the Ministry of Education, Science and Technology, Korea and the G. W. Woodruff School of Mechanical Engineering at Georgia Institute of Technology.

\section{References}

[1] D. Garlotta, “A literature review of poly(lactic acid)," Journal of Polymers and the Environment, vol. 9, no. 2, pp. 63-84, 2001.

[2] R. E. Drumright, P. R. Gruber, and D. E. Henton, "Polylactic acid technology," Advanced Materials, vol. 12, pp. 1841-1846, 2000.

[3] J. Lunt, "Large-scale production, properties and commercial applications of poly lactic acid polymers," Polymer Degradation and Stability, vol. 59, no. 1-3, pp. 145-152, 1998.

[4] O. Martin and L. Avérous, "Poly(lactic acid): plasticization and properties of biodegradable multiphase systems," Polymer, vol. 42, no. 14, pp. 6209-6219, 2001.

[5] H. Tsuji and Y. Ikada, "Properties and morphologies of poly(1lactide): 1 . Annealing condition effects on properties and morphologies of poly(l-lactide)," Polymer, vol. 36, no. 14, pp. 2709-2716, 1995.

[6] L. Fambri, A. Pegoretti, R. Fenner, S. D. Incardona, and C. Migliaresi, "Biodegradable fibres of poly(L-lactic acid) produced by melt spinning," Polymer, vol. 38, no. 1, pp. 79-85, 1997.

[7] S. O. Han, M. Karevan, M. A. Bhuiyan, J. H. Park, and K. Kalaitzidou, "Effect of exfoliated graphite nanoplatelets on the mechanical and viscoelastic properties of poly(lactic acid) biocomposites reinforced with kenaf fibers," Journal of Materials Science, vol. 47, pp. 3535-3543, 2012.

[8] M. S. Huda, L. T. Drzal, A. K. Mohanty, and M. Misra, "Effect of fiber surface-treatments on the properties of laminated biocomposites from poly(lactic acid) (PLA) and kenaf fibers," Composites Science and Technology, vol. 68, no. 2, pp. 424-432, 2008.

[9] S. Serizawa, K. Inoue, and M. Iji, "Kenaf-fiber-reinforced poly (lactic acid) used for electronic products," Journal of Applied Polymer Science, vol. 100, no. 1, pp. 618-624, 2006.

[10] S. Ochi, "Mechanical properties of kenaf fibers and kenaf/PLA composites," Mechanics of Materials, vol. 40, no. 4-5, pp. 446452, 2008.

[11] T. Villmow, P. Pötschke, S. Pegel, L. Häussler, and B. Kretzschmar, "Influence of twin-screw extrusion conditions on the dispersion of multi-walled carbon nanotubes in a poly(lactic acid) matrix," Polymer, vol. 49, no. 16, pp. 3500-3509, 2008.

[12] C.-S. Wu and H.-T. Liao, "Study on the preparation and characterization of biodegradable polylactide/multi-walled carbon nanotubes nanocomposites," Polymer, vol. 48, no. 15, pp. 4449-4458, 2007. 
[13] D. G. Miloaga, H. A. A. Hosein, M. J. Rich, K. Kjoller, and L. T. Drzal, "Scanning probe thermal analysis of polylactic acid/ exfoliated graphite nanoplatelet (xGnP) nanocomposites," Journal of Biobased Materials and Bioenergy, vol. 2, no. 1, pp. 78-84, 2008.

[14] M. Murariu, A. L. Dechief, L. Bonnaud et al., "The production and properties of polylactide composites filled with expanded graphite," Polymer Degradation and Stability, vol. 95, no. 5, pp. 889-900, 2010.

[15] M. Tait, A. Pegoretti, A. Dorigato, and K. Kalaitzidou, "The effect of filler type and content and the manufacturing process on the performance of multifunctional carbon/poly-lactide composites," Carbon, vol. 49, no. 13, pp. 4280-4290, 2011.

[16] I.-H. Kim and Y. G. Jeong, "Polylactide/exfoliated graphite nanocomposites with enhanced thermal stability, mechanical modulus, and electrical conductivity," Journal of Polymer Science $B$, vol. 48 , no. 8, pp. 850-858, 2010.

[17] M.-A. Paul et al., "New nanocomposite materials based on plasticized poly(l-lactide) and organo-modified montmorillonites: thermal and morphological study," Polymer, vol. 44, pp. 443-450, 2003.

[18] S. S. Ray and M. Okamoto, "Biodegradable polylactide and its nanocomposites: opening a new dimension for plastics and composites," Macromolecular Rapid Communications, vol. 24, no. 14, pp. 815-840, 2003.

[19] L. Jiang, J. Zhang, and M. P. Wolcott, "Comparison of polylactide/nano-sized calcium carbonate and polylactide/montmorillonite composites: reinforcing effects and toughening mechanisms," Polymer, vol. 48, no. 26, pp. 7632-7644, 2007.

[20] P. Wambua, J. Ivens, and I. Verpoest, "Natural fibres: can they replace glass in fibre reinforced plastics?" Composites Science and Technology, vol. 63, no. 9, pp. 1259-1264, 2003.

[21] A. K. Mohanty, M. Misra, and G. Hinrichsen, "Biofibres, biodegradable polymers and biocomposites: an overview," Macromolecular Materials and Engineering, vol. 276, pp. 1-24, 2000.

[22] J. E. Riccieri, L. H. De Carvalho, and A. Vázquez, "Interfacial properties and initial step of the water sorption in unidirectional unsaturated polyester/vegetable fiber composites," Polymer Composites, vol. 20, no. 1, pp. 29-37, 1999.

[23] Y. H. Han, S. O. Han, D. Cho, and H. I. Kim, "Dynamic mechanical properties of natural fiber/polymer biocomposites: the effect of fiber treatment with electron beam," Macromolecular Research, vol. 16, no. 3, pp. 253-260, 2008.

[24] A. K. Mohanty, M. A. Khan, and G. Hinrichsen, "Surface modification of jute and its influence on performance of biodegradable jute-fabric/Biopol composites," Composites Science and Technology, vol. 60, no. 7, pp. 1115-1124, 2000.

[25] Y. H. Han, S. O. Han, D. Cho, and H. I. Kim, "Kenaf/polypropylene biocomposites: effects of electron beam irradiation and alkali treatment on kenaf natural fibers," Composite Interfaces, vol. 14, no. 5-6, pp. 559-578, 2007.

[26] D. Feng, D. F. Caulfield, and A. R. Sanadi, "Effect of compatibilizer on the structure-property relationships of kenaffiber/polypropylene composites," Polymer Composites, vol. 22, no. 4, pp. 506-517, 2001.

[27] M. Jonoobi, K. Oksmand Niska, J. Harun, A. Shakeri, and M. Misra, "Chemical composition, crystallinity, and thermal degradation of bleached and unbleached kenaf bast (Hibiscus cannabinus) pulp and nanofibers," BioResources, vol. 4, no. 2, pp. 626-639, 2009.

[28] J. N. McGovern, "Fibers and vegetable," in Encyclopedia of Polymer Science and Engineering, H. F. Mark, N. Bikales, C. G. Overberger et al., Eds., vol. 7, Wiley Interscience, 1987.
[29] H.-L. Chen and R. S. Porter, "Composite of polyethylene and kenaf, a natural cellulose fiber," Journal of Applied Polymer Science, vol. 54, no. 11, pp. 1781-1783, 1994.

[30] J. H. Chen, F. C. Tsai, Y. H. Nien, and P. H. Yeh, "Isothermal crystallization of isotactic polypropylene blended with low molecular weight atactic polypropylene. Part I. Thermal properties and morphology development," Polymer, vol. 46, no. 15, pp. 5680-5688, 2005.

[31] J. R. Isasi, R. G. Alamo, and L. Mandelkern, "The thermal expansion of the monoclinic unit cell of isotactic polypropylene," Journal of Polymer Science B, vol. 35, no. 17, pp. 29452949, 1997.

[32] Q. Zheng, Y. Shangguan, S. Yan, Y. Song, M. Peng, and Q. Zhang, "Structure, morphology and non-isothermal crystallization behavior of polypropylene catalloys," Polymer, vol. 46, no. 9, pp. 3163-3174, 2005.

[33] C. Clemons and A. R. Sanadi, "Instrumented impact testing of kenaf fiber reinforced polypropylene composites: effects of temperature and composition," Journal of Reinforced Plastics and Composites, vol. 26, no. 15, pp. 1587-1602, 2007.

[34] D. R. Burfield, "Polymer glass transition temperatures," Journal of Chemical Education, vol. 64, no. 10, p. 875, 1987.

[35] M. P. Stevens, Polymer Chemistry: An Introduction, Oxford University Press, 3rd edition, 1999.

[36] S. Doroudiani, C. B. Park, and M. T. Kortschot, "Processing and characterization of microcellular foamed high-density polyethylene/isotactic polypropylene blends," Polymer Engineering and Science, vol. 38, no. 7, pp. 1205-1215, 1998.

[37] A. R. Sanadi and D. F. Caulfield, "Transcrystalline interphases in natural fiber-PP composites: effect of coupling agent," Composite Interfaces, vol. 7, no. 1, pp. 31-43, 2000.

[38] S. M. Ogbomo, K. Chapman, C. Webber, R. Bledsoe, and N. A. D'Souza, "Benefits of low kenaf loading in biobased composites of poly(l-lactide) and kenaf fiber," Journal of Applied Polymer Science, vol. 112, no. 3, pp. 1294-1301, 2009.

[39] L. Suryanegara, A. N. Nakagaito, and H. Yano, "The effect of crystallization of PLA on the thermal and mechanical properties of microfibrillated cellulose-reinforced PLA composites," Composites Science and Technology, vol. 69, no. 7-8, pp. 11871192, 2009.

[40] M. Murariu, A. Da Silva Ferreira, P. Degée, M. Alexandre, and P. Dubois, "Polylactide compositions. Part 1: effect of filler content and size on mechanical properties of PLA/calcium sulfate composites," Polymer, vol. 48, no. 9, pp. 2613-2618, 2007.

[41] T. A. Huy, R. Adhikari, T. Lüpke, S. Henning, and G. H. Michler, "Molecular deformation mechanisms of isotactic polypropylene in $\alpha$ - and $\beta$-crystal forms by FTIR spectroscopy," Journal of Polymer Science B, vol. 42, no. 24, pp. 4478-4488, 2004. 

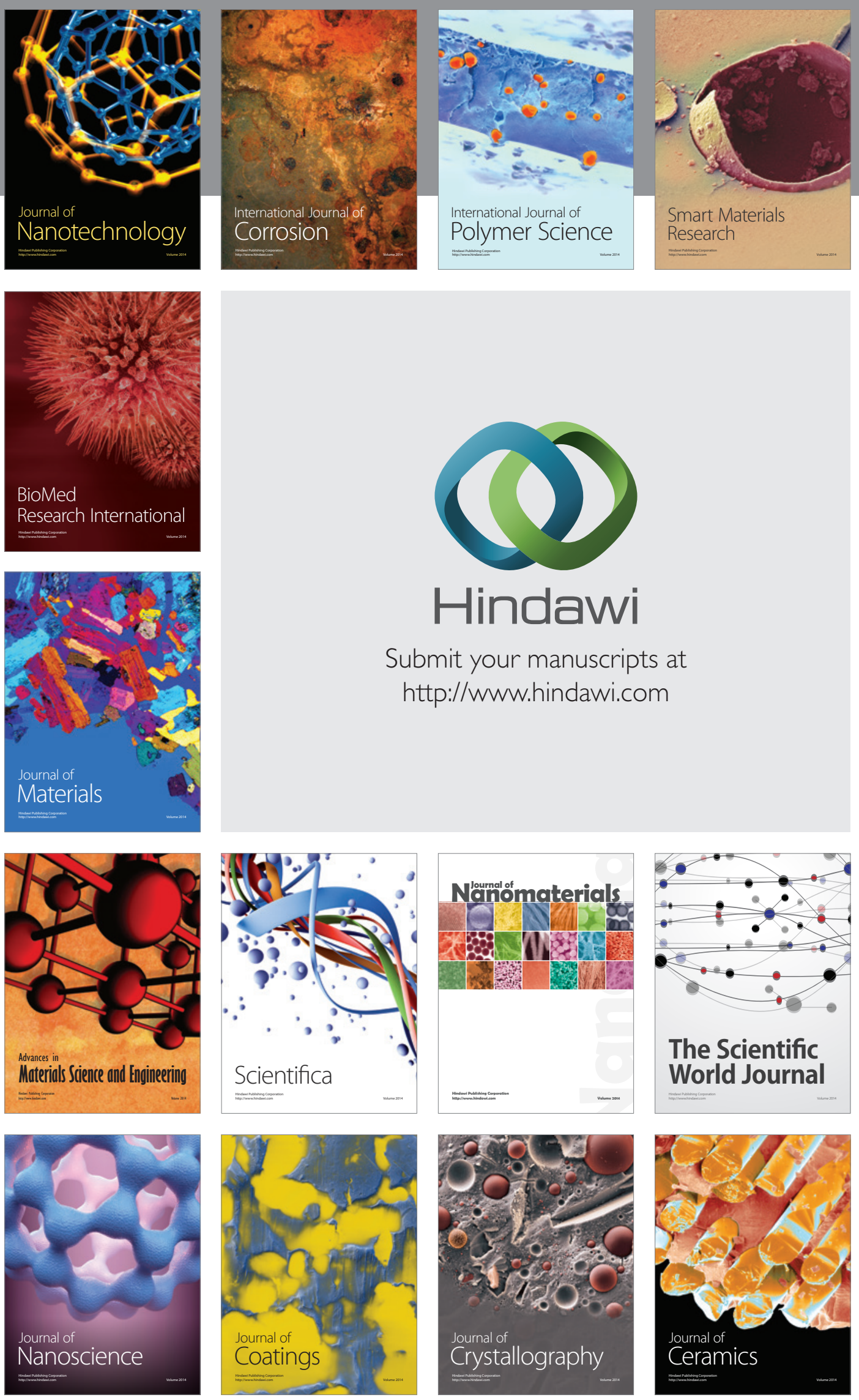

The Scientific World Journal

Submit your manuscripts at

http://www.hindawi.com

\section{World Journal}

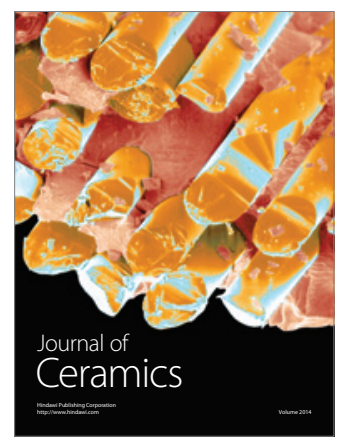

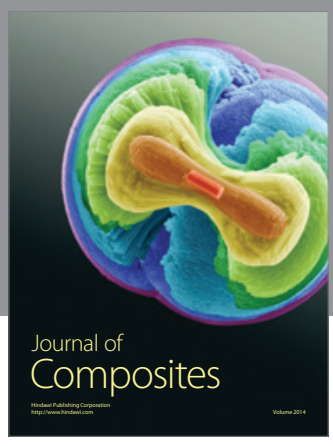
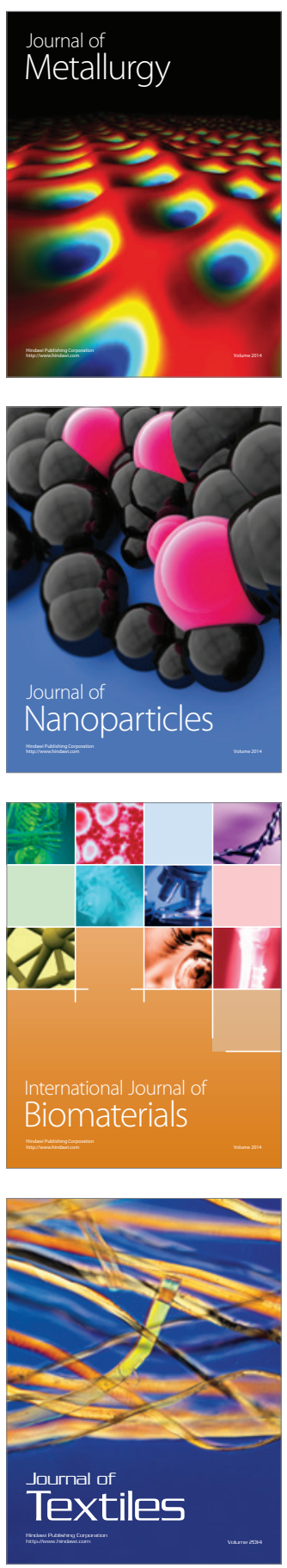